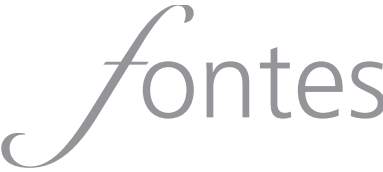

Luiz Salgado Neto

UFRJ (doutorando)

salgado_neto@yahoo.com.br

\section{Relatório Harrison (1945)}

\section{Apresentação}

O chamado "Relatório Harrison" é uma das mais relevantes fontes referentes à situação dos sobreviventes dos campos de concentração após o fim da Segunda Guerra Mundial. Datado de agosto de 1945, foi oficialmente denominado "Relatório da Missão à Europa para investigar as condições e necessidades daquelas, entre as pessoas deslocadas nos países liberados da Europa Ocidental e na área SHAEF da Alemanha - com particular referência aos refugiados judeus - que possivelmente são apátridas ou não-repatriáveis". O relato mostra um quadro extremamente precário dos chamados "DPs" [Displaced Persons - Pessoas Deslocadas, Pessoas Desalojadas], ou seja, as pessoas que, em função da guerra, haviam perdido suas moradias ou não poderiam retornar para seus países de origem. ${ }^{2}$

O autor do relatório foi Earl G. Harrison, ex-Comissário de Imigração dos Estados Unidos e então Decano da Escola de Direito da Universidade da Pensilvânia. A missão originou-se de uma ordem do Presidente norteamericano Harry Truman (1945-1953), diante da pressão interna para que o governo dos Estados Unidos adotasse alguma medida para aliviar a precária condição em que se encontravam os sobreviventes dos campos de concentração, nas áreas ocupadas pelos Estados Unidos na Alemanha, particularmente os judeus, que eram as principais vítimas do nazismo.

A fonte mostra um quadro extremamente precário dos sobreviventes do Holocausto e nos leva a refletir sobre o grau de relevância que os líderes dos governos Aliados atribuíram às vítimas civis, tanto durante a guerra como após a vitória sobre o Eixo.

Nesse sentido, o Relatório Harrison se configura como uma fonte fundamental para os estudiosos do Holocausto e para quem se dedica a pesquisar a situação dos judeus sobreviventes no pós-guerra. Aliás, 0 documento está disponível na Internet por meio do sítio eletrônico dedicado

\footnotetext{
1 Harrison Report - "Mission to Europe to inquire into the condition and needs of those among the displaced persons in the liberated countries of Western Europe and in the SHAEF area of Germany - with particular reference to the Jewish refugees - who may possibly be stateless or non-repatriable" [August, 1945]. Dwight D. Eisenhower's Pre-Presidential Papers, Box 116, Truman Harry S. (4); NAID \#12007695. Disponivel em: <http://www.eisenhower.archives.gov/research/ online_documents/holocaust/Report_Harrison.pdf>. Acesso em: 10 fev. 2015.

20 termo em inglês utilizado em relatórios, discussões e na imprensa era "Displaced Persons". Essa expressão, muitas vezes abreviada como DPs, englobava as pessoas que foram encontradas nos campos de concentração após os avanços das forças antinazistas. Porém, essas pessoas haviam perdido suas casas e não poderiam retornar para seus locais de origem, tendo de permanecer durante algum tempo nos campos de concentração. No caso específico dos judeus, havia também aqueles que não queriam retornar para os lugares onde viviam antes da guerra. A expressão poderia também ser traduzida como "pessoas desenraizadas" ou "pessoas deslocadas". Utilizo o termo em português "desalojado" por entender que denota melhor a situação dos sobreviventes do nazismo. Segundo o dicionário consultado, desalojar significa: 1) "fazer sair ou sair (alguém ou algo) de alojamento, de lugar em que está ou em que reside"; 2) "forçar a abandonar um posto, uma posição; expulsar". Antônio Houaiss e Mauro de Sales Villar. Dicionário Houaiss da Língua Portuguesa. Rio de Janeiro: Objetiva, 2004.
} 
a Dwight Eisenhower - que em agosto de 1945, era o Governador Militar da zona ocupada pelos Estados Unidos na Alemanha - e integra um amplo conjunto de fontes sobre o Holocausto, junto a outros relatórios, fotografias, declarações, coletivas de imprensa e correspondências.

O Relatório Harrison é importante também para quem se dedica a analisar a política externa norte-americana no período posterior à Segunda Guerra Mundial, pois permite visualizar alguns aspectos menos debatidos da política externa de Harry Truman. Em meio ao acirramento da Guerra Fria, o Relatório Harrison demonstra uma ação externa dos Estados Unidos que não era conduzida, tendo em vista a disputa com a União Soviética - tópico que, em geral, recebe a maior atenção dos pesquisadores.

Além disso, o Relatório Harrison possui relevância também pelo seu impacto político na História da Palestina, sendo formulado em um período marcado pelo agravamento do conflito entre sionistas e árabes. Ao ter em suas mãos o Relatório Harrison, o Presidente Truman passou a advogar junto à Grã-Bretanha (que controlava politicamente a Palestina desde 1917), sobre a entrada de 100 mil judeus sobreviventes na Palestina à guisa de ajuda humanitária. Tal atitude revela os primeiros passos efetivos da atuação dos Estados Unidos como um terceiro ator no conflito da Palestina. A proposta de Truman foi condenada, tanto pelos árabes quanto pelo governo da Grã-Bretanha, que alegava que a entrada desse contingente de refugiados traria graves problemas para a administração de um território já conflagrado.

A fonte demonstra, principalmente, que mesmo com o fim da guerra e com a derrota do nazismo, os sobreviventes judeus ainda passavam por sofrimentos indizíveis. Ou seja, a derrota do Eixo não significou a imediata melhora nas condições dos judeus europeus, que ainda tinham seus destinos discutidos e decididos em gabinetes de governo, que nem sempre viam a situação em toda a sua gravidade.

Portanto, ao apresentar de forma tão explícita as péssimas condições dos sobreviventes dos campos de extermínio e por seu tom crítico quanto aos governos das potências vencedoras, o Relatório Harrison teve uma importância significativa nos acontecimentos posteriores e se apresenta como uma fonte valiosa para os estudos históricos que lidam com os temas do Holocausto, política externa norte-americana no pós-Segunda Guerra e Questão Palestina. 


\section{Relatório de Earl G. Harrison}

Missão à Europa para investigar a condição e as necessidades daqueles dentre as pessoas desalojadas ${ }^{3}$ nos países liberados da Europa Ocidental e na área SHAEF ${ }^{4}$ da Alemanha - com particular referência aos refugiados judeus - que possivelmente podem estar sem nacionalidade ou serem nãorepatriáveis.

Londres, Inglaterra

Ao Presidente,

Casa Branca,

Washington.

Prezado Senhor Presidente,

Em resposta à sua carta de 22 de junho de 1945, eu tenho a honra de apresentar ao senhor um relatório parcial sobre minha recente missão à Europa para investigar: (1) as condições sob as quais estão vivendo atualmente as pessoas desalojadas e, particularmente, aquelas que podem estar sem nacionalidade ou serem não-repatriáveis, especialmente na Alemanha e na Áustria; (2) as necessidades de tais pessoas; (3) como tais necessidades estão sendo atendidas atualmente pelas autoridades militares, pelos governos de residência e pelos órgãos internacionais e privados de assistência; e (4) a perspectiva das pessoas possivelmente não-repatriáveis quanto aos seus futuros destinos.

Fui instruído a dedicar particular atenção aos problemas, necessidades e perspectivas dos refugiados judeus entre as pessoas desalojadas, especialmente na Alemanha e na Áustria. Assim, o relatório, particularmente esse relatório parcial, lida principalmente com este grupo.

Em várias ocasiões, as vítimas da perseguição nazista expressaram apreço pelo fato do Governo dos Estados Unidos estar interessado nelas. Como meu relatório demonstra, os refugiados precisam de atenção e ajuda. Até este momento, eles foram "liberados" mais no sentido militar, do que verdadeiramente. Pelas razões apresentadas no relatório, seus problemas específicos, até agora, não têm obtido atenção em qualquer medida apreciável; consequentemente, eles sentem que, sendo de muitas maneiras as primeiras e piores vítimas do nazismo, eles estão sendo negligenciados por seus libertadores.

A meu pedido, o Departamento de Estado autorizou o Dr. Joseph J. Schwartz a se juntar a mim nesta missão. Ao Dr. Schwartz, Diretor europeu do Comitê Americano Conjunto de Distribuição, foi dada autorização para se ausentar desta organização com o objetivo de me acompanhar. Sua ampla e diversificada experiência em problemas relativos a refugiados, assim como sua familiaridade com 0 Continente e o povo, faz do Dr. Schwartz o mais valioso associado; este relatório representa nossas visões, conclusões e recomendações comuns.

Em várias etapas da viagem, eu tive, também, a assistência do Sr. Patrick M. Malin, Vice-Diretor do Comitê Intergovernamental sobre Refugiados ${ }^{5}$ e o Sr. Herbert Katzski, do Conselho para Refugiados de

3 Supreme Headquarters of the Allied Expeditionary Forces - Quartel-General Supremo das Forças Expedicionárias Aliadas.

4 Intergovernmental Committee on Refugees. Agência intergovernamental criada em 1938 por iniciativa do Presidente Franklin Roosevelt.

5 War Refugee Board. Órgão do governo dos Estados Unidos criado pelo Presidente Franklin Roosevelt em janeiro de 1944. 
Guerra ${ }^{6}$. Esses senhores, da mesma forma, têm uma considerável experiência em matérias de refugiados. Sua assistência e cooperação são as mais úteis no curso deste estudo.

\section{ALEMANHA E ÁUSTRIA}

\section{Condições}

(1) Falando de maneira geral, três meses depois do Dia $V-E^{7}$ e mesmo muito depois da liberação dos grupos individuais, muitos judeus desalojados e outros possivelmente não repatriáveis estão vivendo sob guarda, atrás de cercas de arame farpado, em campos de diversas classificações (construídos pelos alemães para os trabalhadores-escravos judeus), incluindo alguns dos mais notórios campos de concentração, Lotados, frequentemente em más condições sanitárias e, geralmente, em péssimas condições, em completa ociosidade, sem qualquer oportunidade, exceto de forma sub-reptícia, de se comunicar com o mundo exterior, aguardando, com esperança, alguma palavra de encorajamento e ação em seu nome.

(2) Embora haja uma notória melhora na saúde daqueles que sobreviveram ao programa nazista de perseguição e com o objetivo de matar pela fome, há muitos casos comoventes de má nutrição, tanto entre os hospitalizados quanto entre a população do campo em geral. A taxa de mortalidade tem se mantido alta desde a liberação, como era esperado. Um Capelão do Exército, um Rabino, compareceu pessoalmente, desde a liberação, a 23.000 sepultamentos (90\% deles judeus) somente em Bergen-Belsen ${ }^{8}$, um dos maiores e mais terríveis campos de concentração, onde, incidentalmente, a despeito de persistentes relatórios em contrário, quatorze mil pessoas desalojadas ainda vivem, incluindo um número de mais de sete mil judeus. Em muitos dos campos e centros, incluindo aqueles onde há sérios casos de fome, há uma notória e séria falta de suprimentos médicos necessários.

(3) Embora alguns Comandantes de Campo tenham buscado, a despeito das muitas óbvias dificuldades, encontrar roupas de um tipo ou de outro para as pessoas sob sua responsabilidade, muitos dos judeus desalojados, no final de julho, não possuíam outras roupas além do uniforme do campo de concentração - na verdade, um hediondo significado do pijama listrado - enquanto outros, para seu pesar, são obrigados a usar uniformes da S.S. Alemã. Pode-se questionar qual roupa eles odeiam mais.

(4) Com poucas notáveis exceções, nenhum programa, atividade ou esforço organizado para reabilitação tem sido realizado e os internos, pois é isso que eles literalmente são, têm pouco a fazer, exceto sobreviver nessa situação, na incerteza sobre seu futuro e, o que é mais desafortunado, fazer comparações entre seu tratamento "sob os alemães" e "após a liberação". Depois de saber que eles não estão mais em perigo das câmaras de gás, tortura e outras formas de morte violenta, eles veem - e há - pouca mudança. O moral daqueles que estão sem nacionalidade ou que não desejam retornar para os países de origem está muito baixo. Eles testemunharam grande atividade e eficiência no retorno de pessoas às suas casas, mas não ouvem e não veem nada sobre planos para eles e, consequentemente, eles pensam e, frequentemente

6 V-E Day - Dia da Vitória na Europa, 7 de maio de 1945.

7 Os campos formavam um complexo próximo às cidades alemãs de Bergen e Belsen, localizadas no Distrito de Celle, na Baixa Saxônia, a cerca de 280 km de Berlim.

8 American Joint Distribution Committee. Organização fundada em 1914 em Nova York, cujo objetivo principal é arrecadar fundos para prestar assistência a judeus em dificuldades ou vítimas de perseguições. 
questionam, o que significa "liberação". Essa situação é consideravelmente agravada onde, como em muitos casos, eles têm a possibilidade de olhar de seus quarteirões lotados e desprotegidos a população civil alemã, particularmente nas áreas rurais, levando, à mostra de todos, uma vida normal em suas próprias casas.

(5) A maior inquietação dessas vítimas da guerra e dos nazistas está relacionada aos parentes esposas, maridos, pais, filhos. A maioria deles foi separada por três, quatro ou cinco anos e não consegue entender o porquê de os libertadores não realizaram imediatamente um esforço organizado para reunir os grupos familiares. A maioria dos raros casos em que algo foi feito nesse sentido, foi produto de ações informais das próprias pessoas desalojadas, com a ajuda de devotos Capelães do Exército, frequentemente

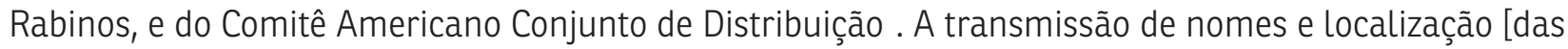
pessoas] pela Divisão de Guerra Psicológica em Luxemburgo tem sido útil, embora a falta de equipamentos receptores esteja prejudicando a efetividade do programa. Mesmo onde, como tem acontecido, a informação sobre parentes vivendo em outros campos de concentração na Alemanha é recebida, a obtenção da permissão ou de assistência para seguir a informação depende da atitude pessoal e da disposição do Comandante de Campo. Alguns Comandantes de Campo são bastante rígidos neste caso, enquanto outros fazem vários esforços para reunir os grupos familiares.

(6) É difícil avaliar com precisão a situação alimentar, pois deve-se ter em mente o fato de que, muito geralmente, os alimentos são escassos e é provável que isso se agrave durante o inverno que se aproxima. Por outro lado, apresentando a situação factual, deve-se questionar por quanto tempo muitas dessas pessoas, particularmente aquelas que estão há muito tempo expostas à perseguição e à fome, podem sobreviver com uma dieta composta principalmente de café e pão, que não cumpre a quantidade calórica. Em muitos campos, as 2.000 calorias incluem 1.250 calorias de um pão preto, úmido e de gosto ruim. Eu tive uma nítida impressão e muitas informações substanciais que grande parte da população alemã - novamente e principalmente nas áreas rurais - têm à disposição uma dieta mais variada e mais palatável do que a das pessoas desalojadas. Os Comandantes de Campo apresentam suas solicitações ao burgomestre alemão e muitos parecem aceitar qualquer coisa que ele entrega como se fosse o melhor que está acessivel.

(7) Muitos dos prédios nos quais as pessoas desalojadas estão vivendo são claramente inadequados para o uso no inverno e em todo lugar há grande preocupação sobre a previsão de uma completa falta de combustivel. Há imensa probabilidade que aproximadamente um milhão de pessoas desalojadas estarão na Alemanha e na Áustria quando o inverno chegar. A perspectiva em muitas áreas, com relação a abrigo, alimentação e combustível, é absolutamente sombria.

II

\section{NECESSIDADES DOS JUDEUS}

Apesar de ser impossível declarar de forma acurada o número de judeus, agora nesta parte da Alemanha que não está sob ocupação russa, todas as indicações apontam para o fato que o número é pequeno, provavelmente o número máximo é de cem mil; algumas pessoas bem informadas afirmam que o número é consideravelmente menor. Os principais grupos nacionais são poloneses, húngaros, romenos, alemães e austríacos.

A primeira e mais exata necessidade dessas pessoas é o reconhecimento de seu status atual e, neste 
ponto, eu estou falando dos judeus. A maioria deles passou anos no pior dos campos de concentração. Em muitos casos, embora toda a extensão ainda não seja conhecida, eles são os únicos sobreviventes de suas famílias e muitos têm passado pelo sofrimento de testemunhar a destruição de seus amados. Compreensivelmente, portanto, sua presente condição física e mental, é muito pior de que a de qualquer outro grupo.

Enquanto as diretrizes políticas da SHAEF (agora Executivo Conjunto para Pessoas Desalojadas) reconheçam formalmente pessoas perseguidas, incluindo nacionais inimigos e ex-inimigos, como uma das categorias especiais de pessoas desalojadas, a prática geral segue apenas critérios nacionais. Embora normalmente reconheçamos que não é desejável destacar grupos raciais e religiosos de suas nacionalidades, a grande verdade é que por muito tempo os nazistas criaram um grupo com necessidades especiais. Judeus como judeus (não como membros de seus grupos nacionais), têm sido mais severamente vitimados que os membros não-judeus das mesmas ou de outras nacionalidades.

Quando eles são considerados apenas como membros de grupos nacionais, isso tem como resultado o fato que uma atenção especial não pode ser dada às suas, reconhecidamente, maiores necessidades, porque alguns argumentam, isso se configuraria um tratamento especial e causaria problemas com a porção não-judaica do grupo nacional particular.

Assim, há uma abordagem notavelmente irrealista do problema. Recusar reconhecer os judeus como tal tem o efeito, nessa situação, de fechar os olhos para a bárbara perseguição que sofreram, que já fez deles um grupo separado com maiores necessidades.

Sua segunda maior necessidade apenas pode ser apresentada discutindo o que penso ser.

\section{ANSEIOS QUANTO AOS FUTUROS DESTINOS}

(1) Por razões que são óbvias e que não precisam ser detalhadas, a maioria dos judeus quer deixar a Alemanha e a Áustria o mais breve possível. Esta é a sua primeira e maior vontade manifestada e apesar desse relatório necessariamente lidar com outras necessidades presentes na situação, muitas das próprias pessoas temem outras sugestões ou planos para seu benefício, por causa da possibilidade de que a atenção possa ser, com isso, desviada da matéria de suma importância, que é sua saída da Alemanha. Seu desejo de deixar a Alemanha é o mais urgente. A vida que eles levaram durante os dez últimos anos, uma vida de medo, de caminhos errantes e de tortura física, os tornou impacientes com o atraso. Eles querem ser levados para a Palestina imediatamente, exatamente como outros grupos nacionais estão sendo repatriados para seus lares. Eles não veem com agrado a ideia de aguardar em ociosidade e em desconforto em um campo na Alemanha por muitos meses, até que uma solução seja vagarosamente encontrada para eles.

(2) Alguns desejam retornar para seus países de nacionalidade, mas para isso, há uma considerável variação nacional. Pouquíssimos judeus poloneses ou bálticos querem retornar para seus países; as mais altas porcentagens dos grupos húngaros e romenos querem retornar, embora alguns façam questão de dizer que isso pode ser apenas temporariamente, com o objetivo de ver seus parentes. Alguns dos judeus alemães, especialmente aqueles que mantiveram casamentos mistos, preferem ficar na Alemanha.

(3) Quanto aos possíveis locais de reassentamento, para aqueles que podem estar sem nacionalidade ou que não querem voltar para suas casas, a Palestina é, de forma definitiva e preeminente, a primeira escolha. Muitos já têm parentes lá, enquanto outros, tendo experimentado a intolerância e a perseguição em seus países de origem por anos, pensam que apenas na Palestina eles serão bem-vindos, encontrarão 
paz e sossego e receberão uma oportunidade de viver e trabalhar. No caso dos judeus poloneses e bálticos, o desejo de ir para a Palestina é baseado, na grande maioria dos casos, em um amor pelo país e uma devoção ao ideal sionista. É verdade, também, contudo, que há muitos que desejam ir para a Palestina, porque eles perceberam que sua oportunidade de serem admitidos nos Estados Unidos ou em qualquer outro país no Hemisfério Ocidental é limitada, senão impossível. Qualquer que seja o motivo que os estimule a se voltar para a Palestina, sem dúvida é verdade que a grande maioria dos judeus, agora na Alemanha, não quer retornar para aqueles países de onde eles vieram.

(4) A Palestina, apesar de ser claramente a escolha da maioria, não é o único lugar de possível emigração. Alguns, mas o número não é grande, querem emigrar para os Estados Unidos, onde eles têm parentes, outros para a Inglaterra, para os Domínios Britânicos, ou para a América do Sul.

Assim, a segunda maior necessidade é a pronta elaboração de um plano para retirar da Alemanha e da Áustria, o maior número de pessoas possível que queiram.

Em suma, as necessidades e os desejos dos grupos judeus dentre as pessoas desalojadas podem ser simplesmente declarados: entre as suas necessidades físicas estão roupas, sapatos (que são mais severamente necessários), alimentos mais diversificados e palatáveis, remédios, camas e colchões, materiais de leitura. As roupas para os campos também foram requisitadas da população alemã, e se não há suficiente quantidade para ser obtida, se a população alemã não estiver disposta ou não for obrigada a doar quantidades suficientes, os internos ficarão particularmente amargurados sobre o estado de suas vestimentas, quando eles virem como a população alemã está bem vestida. A população alemã, ainda hoje, é a melhor vestida em toda a Europa.

III

\section{FORMAS PELAS QUAIS AS NECESSIDADES ESTÃO SENDO ATENDIDAS}

Exceto por ter sido trazida assistência contra o risco de extermínio, a hospitalização para os casos sérios de fome e alguma melhora geral nas condições, sob as quais as pessoas desalojadas remanescentes se viram obrigadas a viver, relativamente pouco além da etapa de planejamento foi feito, durante o período de repatriação em massa, para atender as necessidades especiais dos grupos anteriormente perseguidos.

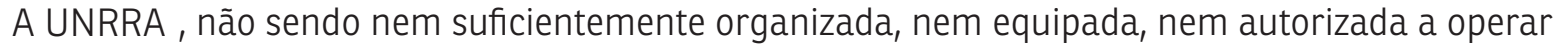
em campos ou centros de pessoas desalojadas em qualquer grande escala, não está em posição de fazer qualquer contribuição substancial para a situação. Infelizmente, tem havido uma tendência da parte de muitos Comandantes de Campo, de não utilizar o pessoal da UNRRA, mesmo no que está acessível, embora seja admitido que em muitas situações isto resultou de experiências desafortunadas, que oficiais do Exército tiveram com o pessoal da UNRRA, os quais não eram qualificados e inadequados para as responsabilidades envolvidas. Então, também, nas zonas americanas e britânicas, frequentemente ocorre que o pessoal da UNRRA não inclui membros de fala inglesa e isso prejudica as apropriadas relações de trabalho.

Nessas circunstâncias, a UNRRA, que foi encarregada da responsabilidade de coordenar as atividades de agências privadas de bem-estar social, está em uma posição incômoda, quando tem que considerar e agir segundo propostas, de um tipo ou de outro, submetidas por agências qualificadas que ajudariam e poderiam suplementar as responsabilidades militares e da UNRRA. 0 resultado, até este momento, é que pouquíssimas agências privadas de bem-estar social estão trabalhando com as pessoas desalojadas, incluindo os judeus, embora a situação requeira seus serviços de diferentes maneiras.

Deve ser dito, também, que por causa de sua ocupação prévia com a repatriação em massa e por 
causa das dificuldades referentes a abrigo, pessoal e transporte, as autoridades militares têm demonstrado considerável resistência à entrada de voluntários, não importa quão qualificados eles sejam, para ajudar a atender as necessidades existentes entre as pessoas desalojadas.

IV

\section{CONCLUSÕES E RECOMENDAÇÕES}

1. Agora que o pior momento da pressão da repatriação em massa terminou, é razoável sugerir que no próximo e talvez mais difícil período, a primeira e não demorada atenção seja dada àqueles que sofreram mais e durante mais tempo.

Especificamente, nos dias imediatamente à frente, os judeus na Alemanha e na Áustria devem ter o primeiro direito na consciência do povo dos Estados Unidos e da Grã-Bretanha e dos militares e de outras pessoas que os representam no trabalho sendo feito na Alemanha e na Áustria.

a) 2. A retirada da Alemanha deve ser o tema, a política e a prática de maior prioridade. Reconhecendo que a repatriação é o mais desejável ponto de partida de todos os envolvidos, os judeus que quiserem retornar aos seus países de origem deveriam ser ajudados a fazê-lo sem demora. Alguma ação especial é necessária para concretizar isso em relação aos países de recepção; ou o consentimento de autoridades militares ou de outras [autoridades] devem ser obtidas com energia e determinação. A menos que essa ou outra ação a ser sugerida seja tomada, substanciais movimentos não-oficiais e não autorizados podem ser esperados, e as pessoas envolvidas estarão, e em minha opinião justificadamente, chegando perto do ponto de loucura. Não deve ser esquecido que muitas dessas pessoas estão agora em desespero, que elas se tornaram acostumadas, sob governo alemão, a empregar quaisquer meios possíveis para atingir seus fins, e que o medo da morte não as impede.

b) Quanto àqueles que não querem, por boas razões, retornar às suas casas, algum rápido plano deve ser realizado. Quanto a isso, a questão da Palestina deve ser enfrentada. Agora que grandes números não estão mais envolvidos e se há qualquer simpatia genuína pelo que esses sobreviventes passaram, alguma alteração do White Paper britânico de $1939^{9}$ deve ser possível sem mais sérias repercussões. Para alguns dos judeus europeus, não há solução aceitável ou mesmo decente para seu futuro a não ser a Palestina. Isso é dito segundo bases puramente humanitárias, sem referências às considerações ideológicas ou políticas em que a Palestina está imersa.

Eu tomei conhecimento, baseado em informações confiáveis, que os certificados para imigração para a Palestina serão praticamente terminados no fim do presente mês (agosto de 1945). 0 que será do futuro? Para qualquer um que visitou os campos de concentração e que conversou com sobreviventes desesperados, nada é tão próximo da calamidade do que contemplar que as portas da Palestina serão fechadas em breve.

A Agência Judaica da Palestina submeteu, ao Governo Britânico, uma petição para que cem mil certificados de imigração adicionais sejam disponibilizados. Um memorando que acompanha a petição faz uma convincente demonstração com respeito à imediata capacidade

9 White Paper: documento oficial britânico emitido em maio de 1939, que limitava a imigração judaica para a Palestina. 
de absorção da Palestina e a presente e real falta de mão-de-obra.

Apesar de haver espaço para diferenças de opinião, quanto ao preciso número de certificados que podem ser considerados razoáveis, não há dúvidas de que, se este pedido for aceito, isso contribuiria muito para uma solução justa para o futuro dos judeus na Alemanha e na Áustria e mesmo para outros judeus desalojados, que também não querem permanecer lá ou retornar aos seus países de nascimento.

Portanto, nenhum outro assunto é tão importante, do ponto de vista dos judeus, na Alemanha e na Áustria e para aqueles em outros lugares que conheceram os horrores dos campos de concentração, como a questão da Palestina.

Segundo informações, o Dr. Hugh Dalton, um proeminente membro do Governo Britânico, teria dito durante a Conferência do Partido Trabalhista em maio de 1945:

Este Partido tem dito e repetido muitas vezes tão recentemente quanto no último mês de abril [...] que neste momento, diante dos indiziveis horrores que foram perpetrados contra os judeus da Alemanha e de outros países ocupados na Europa, é moralmente errado e politicamente indefensável impor obstáculos à entrada na Palestina de qualquer judeu que desejar.

Nós também declaramos claramente que essa não é uma questão que deva ser considerada unicamente de responsabilidade do Governo Britânico; quanto a essa questão, assim como muitas outras, no campo internacional, é indispensável que haja um acordo e uma estreita cooperação entre os Governos Britânico, Americano e Soviético, especialmente se nós desejarmos obter uma situação calma na Palestina e nos países vizinhos [...].

Se isso puder ser entendido como o ponto de vista do novo Governo na Grã-Bretanha, certamente não será algo inapropriado para o Governo dos Estados Unidos expressar seu interesse e apoiar alguma solução equitativa da questão, que torne possível para um número considerável de judeus perseguidos da Europa, agora sem casa [homeless], sob qualquer conceituação justa, serem reassentados na Palestina. Já que essa é a vontade deles e isso é entendido como desejável pela política convencionalmente aceita de permitir grupos familiares de se unirem ou reunirem.

c) Os Estados Unidos devem, sob as leis de imigração existentes, permitir que quantidades razoáveis de tais pessoas venham para cá [Estados Unidos], novamente e particularmente aqueles que têm laços familiares nesse país. Como indicado anteriormente, o número que deseja emigração para os Estados Unidos não é grande.

Se a Grã-Bretanha e os Estados Unidos tomarem as medidas sugeridas, pode ser que, prontamente, outros países estejam dispostos a manter suas portas razoavelmente abertas para tais considerações humanitárias e para demonstrar, por meio de uma postura prática, sua desaprovação da política Nazista, que, infelizmente, envenenou grande parte da Europa.

3. À medida que tal emigração da Alemanha e da Áustria for protelada, alguma imediata solução temporária deve ser encontrada. De qualquer maneira, haverá um número substancial de pessoas perseguidas que não estão fisicamente aptas ou atualmente preparadas para emigração. 
Aqui eu penso fortemente que, maiores e mais intensos esforços devem ser feitos para tirá-los dos campos, pois eles estão doentes por viverem nos campos. Em primeiro lugar, há uma real necessidade para encontrar lugares especializados como: (a) hospitais especializados em tuberculose; e (b) lugares de internação para aqueles que são mentalmente doentes ou que precisam de um período de reabilitação, antes de viverem novamente no mundo mais amplo - em qualquer lugar. Alguns irão requerer, pelo menos, curtos períodos de treinamento ou re-treinamento antes que possam ser realmente cidadãos úteis.

Mas, falando mais geralmente, há uma oportunidade aqui para fornecer algum real significado à política acordada em Potsdam. Se for verdade, como agora parece amplamente reconhecido, que o povo alemão, como um todo, não possui qualquer percepção de culpa com respeito à guerra e às suas causas e resultados, e se a política é para "convencer o povo alemão que eles sofreram uma derrota militar total e que eles não podem escapar da responsabilidade que eles trouxeram sobre eles mesmos", então é difícil entender porque tantas pessoas desalojadas, particularmente aqueles que foram perseguidos e cuja repatriação ou reassentamento será provavelmente postergado, devem ser compelidos a viver em campos precários e superlotados, enquanto o povo alemão, nas áreas rurais, continuam sem ser incomodados em suas casas.

No estado em que as coisas estão agora, parece que nós estamos tratando os judeus assim como os nazistas, com a exceção de que nós não estamos os exterminando. Eles estão em campos de concentração em grandes números, sob nossa guarda militar, ao invés de estarem sob guarda das tropas S.S. Isso nos leva a pensar se o povo alemão, vendo isso, não está supondo que nós estamos seguindo ou, pelo menos, fechando os olhos para a política nazista.

Parece muito mais justo [equitable], e como deveria ser, testemunhar os raros lugares onde oficiais militares destemidos e resolutos têm feito requisições a vilarejos inteiros, para o benefício das pessoas desalojadas, obrigando a população alemã a encontrar moradia onde eles puderem, ou requereram à população local, a abrigar temporariamente um número razoável delas [pessoas desalojadas]. Então as pessoas desalojadas, incluindo os perseguidos, vivem mais como pessoas normais e menos como prisioneiros, criminosos ou como gado arrebanhado. Eles estão na Alemanha, a maioria dos quais e, certamente os judeus, por nenhuma culpa ou vontade própria. Esse fato está sendo demonstrado nesses termos para o povo alemão, mas está sendo feito em uma escala muito reduzida.

Em muitos lugares, contudo, os oficiais do governo militar manifestam total relutância ou indisposição, senão timidez, em causar inconveniência à população alemã. Eles dizem, inclusive, que seu trabalho é fazer com que comunidades trabalhem adequadamente e em boa condição [soundly] novamente, que eles devem "viver com os alemães enquanto os dps (pessoas desalojadas) são um problema apenas temporário". Assim (e eu estou disposto a citar o exemplo), se um grupo de judeus for ordenado a deixar seus temporários abrigos, algo necessário para propósitos militares, e há dois possíveis locais, um bloco de apartamentos (modestos apartamentos) com conveniências e, o outro, uma série de precárias construções com banheiro e área de serviço externos, o oficial local prontamente consegue persuadir o Major da cidade a conceder o último às pessoas desalojadas e guardar o primeiro para os civis alemães que estão retornando.

Essa tendência se manifesta de outras maneiras, nomeadamente, no emprego de civis alemães nos escritórios dos oficiais do governo militar, quando pessoal igualmente qualificado poderia facilmente ser encontrado entre as pessoas desalojadas, cuja repatriação não é iminente. Verdadeiramente, têm havido situações em que pessoas desalojadas, especialmente os judeus, têm encontrado dificuldades para obterem audiências com autoridades do governo militar, porque, ironicamente, eles têm sido obrigados a buscar intermediários alemães que não têm facilitado as coisas.

Quase sempre, está sendo feito um insuficiente uso dos serviços das pessoas desalojadas. Muitas 
delas são capazes e estão ansiosas para trabalhar, mas aparentemente elas não são consideradas a esse respeito. Embora saiba que por vezes há dificuldades de idioma, eu estou convencido de que, tanto dentro quanto fora dos campos, maior uso poderia ser feito dos serviços pessoais daquelas pessoas desalojadas, que muito provavelmente estarão à disposição por algum tempo. Felizmente em alguns campos todo esforço está sendo realizado para utilizar os serviços das pessoas desalojadas e estes estão aptos a serem os melhores campos em todos os aspectos.

4. Levando-se em consideração que: (a) sua evacuação da Alemanha e da Áustria não é imediatamente possível; e (b) que os grupos anteriormente perseguidos não podem ser abrigados nos vilarejos ou abrigos temporários, juntos com a população alemã; eu recomendo urgentemente que campos separados sejam erguidos para judeus ou, pelo menos, para aqueles que desejarem, na falta de uma melhor solução, ser mandados para tais campos. Há algumas razões para isso: (1) uma grande maioria quer isso; (2) este é o único modo pelo qual, administrativamente, suas necessidades e problemas específicos podem ser enfrentados sem acusações de tratamento diferenciado ou (lamentavelmente) acusações de "discriminação", com respeito às agências judaicas agora preparadas e prontas para dar assistência a eles.

Ligado a isso, eu gostaria de enfatizar que não se trata de destacar um grupo particular para dá-lo privilégios especiais. Trata-se de uma questão de elevar a um nível normal a posição de um grupo que foi rebaixado a níveis mais profundos, concebíveis durante anos de uma opressão organizada e desumana. As medidas necessárias para sua restituição não vêm dentro de uma interpretação razoável de tratamento privilegiado e são demandadas por considerações de justiça e humanidade.

Tem havido uma tendência, em alguns lugares, na direção de criarem-se campos separados para aqueles que podem se tornar apátridas ou não-repatriáveis ou cuja repatriação provavelmente será postergada por um tempo. Na verdade, também, isso foi anunciado algum tempo atrás como política da SHAEF, mas na prática isto não significou muito, pois há (compreensivelmente se não levado muito longe) uma recusa em contemplar a possibilidade da condição de apátrida e uma insistência, no interesse de um grande programa de repatriação, a considerar todos como repatriáveis. Isso tem como consequência uma resistência a qualquer coisa no caminho de um planejamento especial para o "núcleo duro", embora todos admitam que isso inevitavelmente irá aparecer. Falando dos campos, deve ser destacado: embora possamos dizer que as condições da Alemanha e Áustria ainda são tais, que certas medidas de controle são necessárias, parece haver pouca justificação para a continuação de cercas de arame farpado, guardas armados e proibição de deixarem os campos, exceto por autorizações que em alguns lugares são concedidas de forma restrita. A prevenção de saques é dada como justificativa para essas medidas duras, mas é interessante que nas porções da área do Sétimo Exército, onde é concedida uma maior liberdade de movimento de entrada e saída dos campos, há muito menos saques do que em outras áreas, onde as pessoas, desejando deixar o campo temporariamente, devem fazer isso para roubar.

5. 0 mais breve possível, a real operação de tais campos deve ser passada para uma agência civil - UNRRA. Esta organização está ciente da fraqueza na atual estrutura e está pressionando para remediála. Ligado a isso, acredita-se que uma maior assistência poderia ser dada pelas autoridades militares, de quem qualquer agência civil na Alemanha e na Áustria hoje é necessariamente dependente para qualquer assunto relacionado à moradia, transporte e a outras questões. Embora seja verdade que os militares têm urgido à UNRRA para ficar preparada para assumir a responsabilidade, é fato que uma insuficiente cooperação de natureza ativa tem sido dada para realizar os objetivos almejados. 
6. Já que, em qualquer circunstância, as autoridades militares devem necessariamente participar do programa para todas as pessoas desalojadas, especialmente quanto à moradia, transporte, segurança e certos suprimentos, é recomendado que haja uma revisão do pessoal militar selecionado para as posições de Comandante de Campo. Alguns servindo atualmente, embora talvez adequados para o trabalho de repatriação em massa, são manifestamente inadequados para a tarefa de longo prazo, de trabalhar em um campo composto de pessoas cuja repatriação ou reassentamento será provavelmente postergado. Oficiais que possuem algum histórico ou experiência em trabalho de assistência social devem ser preferidos e acredita-se que há alguns deles acessíveis. É muito importante que os oficiais selecionados sejam simpáticos ao programa e que eles sejam aptos por temperamento a trabalhar e cooperar com a UNRRA e com outras agências de assistência e de bem-estar.

7. Na pendência do momento em que a UNRRA irá assumir a responsabilidade pelas operações, é desejável que um plano mais amplo de visitas aos campos por um apropriado Grupo de Comando Militar seja instituído. Acredita-se que muitas das condições agora existentes nos campos não seriam toleradas, se fossem conhecidas mais de perto por oficiais comandantes por meio de visitas de inspeção.

8. É urgentemente recomendado que planos para serviços de localização [de familiares] agora sob consideração, sejam acelerados o máximo possível e que, nesta mesma direção, serviços de comunicação, mesmo se apenas por cartão postal, sejam acessíveis às pessoas desalojadas na Alemanha e na Áustria, o mais rápido possível. Compreende-se as dificuldades, mas acredita-se que, se a ansiedade das pessoas, por tanto tempo vítimas de crueldade e perseguição, forem totalmente compreendidas, modos e meios poderiam ser encontrados em um futuro próximo para tornar possível tal comunicação e localização de parentes. Eu acredito, também, que algumas das agências privadas poderiam ser úteis nesse sentido se tivessem a oportunidade de funcionar.

\section{V}

\section{Outros comentários}

Embora eu tenha sido instruído de relatar as condições como eu as encontrei, devo adicionar o que se segue, para tornar o quadro completo:

(1) Uma tarefa gigantesca confrontou os exércitos ocupantes na Alemanha e na Áustria em levar de volta para suas casas, o máximo possível das mais de seis milhões de pessoas desalojadas encontradas nesses países. Menos de três meses depois do Dia $V-E$, mais de quatro milhões dessas pessoas foram repatriadas - uma atuação fenomenal. A primeira impressão que se tem, ao investigar a situação, é de completa admiração pelo que foi realizado pelas autoridades militares, em reduzir tão consideravelmente o tempo necessário previsto para essa estupenda tarefa. Orgulho da mais alta ordem é devido a todas as unidades militares, com respeito a essa fase do trabalho após a batalha. Ao dirigir a atenção para as condições existentes, que inquestionavelmente requerem resolução, não há intenção ou desejo de desvalorizar um ponto das declarações anteriores.

(2) Embora eu não tenha visto, de fato, as condições como elas existiam imediatamente após a liberação, elas me foram descritas em detalhes suficientes para deixar inteiramente claro que tem havido, durante o período de interregno, alguma melhora nas condições em que a maioria das pessoas desalojadas remanescentes está vivendo. Relatórios que chegaram informalmente da Alemanha, vindos dos próprios 
refugiados e de pessoas interessadas em grupos de refugiados, indicam que há uma tendência de não considerar o completo escopo da enorme tarefa e responsabilidades que são enfrentadas pelas autoridades militares. Embora seja compreensível que aqueles que foram perseguidos e também maltratados por tão longo tempo, devem estar impacientes pelo que lhes parece um indevido atraso em atender às suas necessidades específicas, a justiça manda que, ao avaliar o progresso feito, todo o problema e todas das suas ramificações sejam considerados. Meus esforços foram, portanto, pesar bastante cuidadosamente as muitas reclamações feitas a mim no curso de minha investigação, tanto pelas próprias pessoas desalojadas e em seu nome, quanto à luz das muitas responsabilidades que confrontam as autoridades militares.

(3) Embora devido à necessidade de brevidade, este relatório necessariamente consista largamente de declarações gerais, deve ser reconhecido que exceções existem no tocante a praticamente todas essas generalizações. Uma autoridade militar de alta patente previu, anteriormente à minha viagem pela Alemanha e pela Áustria, que eu encontraria, quanto aos campos que continham pessoas desalojadas, "alguns que estão razoavelmente bem, alguns que estão muito mal, com a média estando algo satisfatório". Minha viagem subsequente confirmou essa previsão em todos os aspectos.

Com a finalidade de arquivar esse relatório prontamente, de modo que possivelmente alguns passos corretivos possam ser considerados o mais rápido possível, eu não tive tempo de analisar todas as notas feitas no curso da viagem ou de comentar sobre a situação na França, Bélgica, Holanda ou Suíça, países também visitados. De acordo com isso, eu respeitosamente requeiro que o presente relatório seja considerado de natureza apenas parcial. Os problemas existentes na Alemanha e na Áustria são muito mais sérios e difíceis do que em qualquer dos outros países citados e esse fato, também, pareceu tornar desejável 0 arquivamento de um relatório parcial imediatamente após o término da missão.

Em conclusão, eu gostaria de repetir que a principal solução, de várias maneiras a única solução real do problema, reside na rápida evacuação de todos os judeus não-repatriáveis na Alemanha e na Áustria, que desejarem, para a Palestina. Para ser efetivo, esse plano não deve ser postergado. A urgência da situação deve ser reconhecida. É desumano pedir às pessoas que continuem a viver por qualquer duração sob suas atuais condições. A evacuação dos judeus da Alemanha e da Áustria para a Palestina irá solucionar o problema dos indivíduos envolvidos e irá também remover um problema das autoridades militares que têm de lidar com isso. A habilidade do exército de mover milhões de pessoas rapidamente e eficientemente já foi demonstrada. A evacuação de um número relativamente pequeno de judeus da Alemanha e da Áustria não irá apresentar um grande problema para os militares. Com o fim da guerra japonesa, a situação do transporte marítimo deve também se tornar suficientemente melhor para fazer com que tal empreitada seja exequível. 0 mundo civilizado deve isso a essa porção de sobreviventes de provê-los com um lar, onde eles possam novamente se assentar e começar a viver como seres humanos.

Respeitosamente

Earl G. Harrison 